\title{
Happiness in shrinking cities in Germany
}

\section{A research note}

\section{Ellis Delken}

\begin{abstract}
After decades of urban growth, modern societies now face an increasing number of shrinking cities. What is the impact on the inhabitants of shrinkage of their city? Negative effects dominate in the public discourse, but does growth or shrinkage really matter for the livability in urban environment? In this paper, I take stock of the effect on subjective well-being in present day Germany. Overall satisfaction with life appears not to be lower in shrinking cities and satisfaction with several domains of life even higher. This is not because inhabitants are unaware of the situation of their city, since they appear to be more concerned about job-chances and crime.
\end{abstract}

Keywords Growth and decline of cities · Happiness · Life-satisfaction · Quality of life

Since the fall of the Berlin Wall in 1989 people are leaving former East Germany. The East German economy was dependent on obsolete industries. When the Wall fell, the industry also fell dramatically. A lot of people lost their jobs. Young people moved to the West, resulting in ageing and shrinking of cities. Currently many regions in West Germany are also affected or will suffer a considerable decline in population in the years to come. Birth rate in Germany is very low compared to those in other European countries. At this moment shrinking cities seem to be, at least in Europe, a German phenomenon. That's why I focus on German cities in this research note

Summary of Ellis Delken Master Thesis Sociology at Erasmus University Netherlands under supervision of Prof. Dr. Ruut Veenhoven.

E. Delken $(\bowtie)$

Department of Social Sciences c/o Ruut Veenhoven, Erasmus University Rotterdam, Rotterdam, POB 1738, 3000 DR Rotterdam, The Netherlands

e-mail: Veenhoven@fsw.eur.nl 
Fig. 1 Growing (1), stable (2) and shrinking (3) cities in former East Germany
Fig. 2 Growing (1), stable (2) and shrinking (3) cities in former West Germany
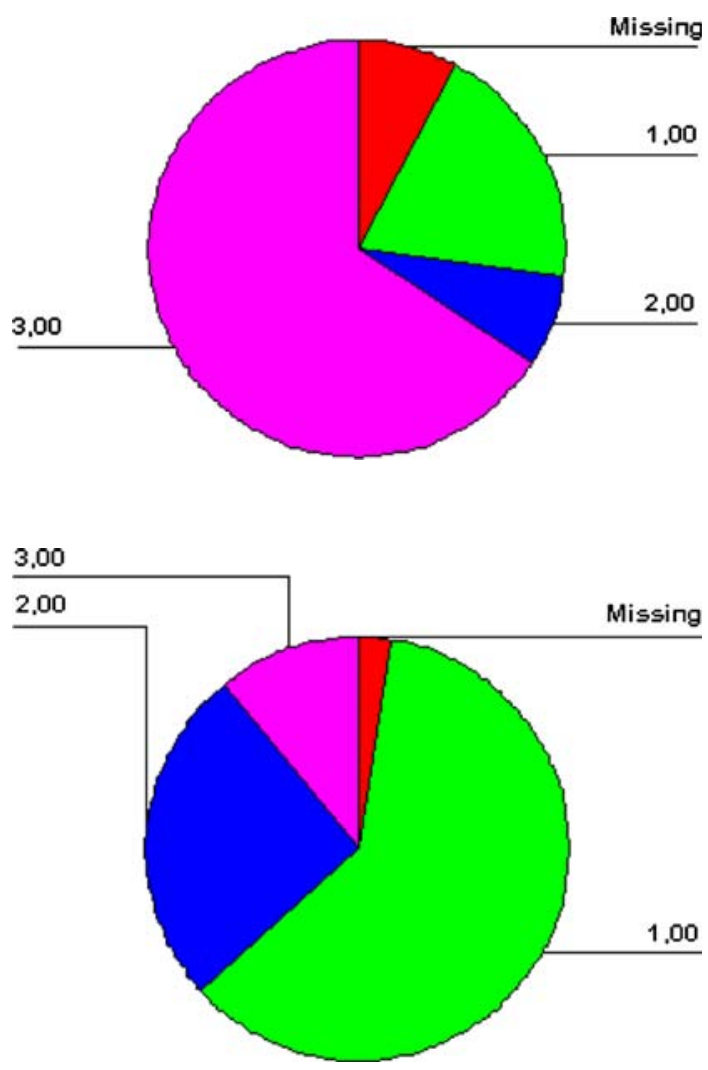

\section{Growing, stable and shrinking cities in Germany}

To determine which German cities are shrinking, remaining stable or growing I used data published by the 'Bundesamt für Bauwesen und Raumordnung'. These data give an overview of all districts ('Kreise') in Germany and their population numbers since 1990 and the population forecasts until 2020. I divided the cities in three groups

1. growing cities: the population grew by 3\% or more from 1990 until 2005.

2. stable cities: the population shrunk by max. $-2.99 \%$ or grew by max. $2.99 \%$ from 1990 until 2005.

3. shrinking cities: the population shrunk by $-3 \%$ or more from 1990 until 2005 .

Germany consists of 439 'Kreise' or districts. From 1990 until 2005, 55\% of the districts grew by $3 \%$ or more; $19 \%$ of the districts were stable ( -3 to $3 \%$ ) and $26 \%$ of the districts shrunk by $3 \%$ or more. ${ }^{1}$

The next two figures show that shrinking cities are found more often in former East Germany than in West Germany (Figs. 1 and 2).

\footnotetext{
${ }^{1}$ It is expected that more districts will shrink in the future; $42 \%$ of the districts will shrink in the period from 2006 until 2020 . About $20 \%$ of the districts will still grow and $38 \%$ will remain stable from 2006 until 2020 (Bundesamt für Bauwesen und Raumordnung).
} 


\section{Quality of life in growing, stable and shrinking cities}

To measure the quality of life in cities, I have focused on subjective well-being. I found information on that matter in the German Socio-Economic Panel (SOEP). The standard questionnaire of that study involves a question on overall life-satisfaction and also several questions on satisfaction with particular life domains. The questions read as follows:

General life-satisfaction: "How satisfied are you with your life, all things considered?"

Domain satisfactions: "How satisfied are you with:"

- your health?

- (if employed) your job?

- your household income?

- your place of dwelling?

- your free time?

- the supply of goods and services in your area?

- local access to public transport?

- the environmental conditions in your area?

- your overall standard of living?

\subsection{Life-satisfaction in shrinking cities}

The $y$-axis in Fig. 3 shows the average satisfaction with life nowadays and the $x$-axis shows the three categories: cities that grew remained stable or shrunk from 1990 until 2005. The data show that it doesn't really matter whether one lives in a growing or shrinking city, but it does matter whether one lives in East or West Germany. The "Wessi's" are more satisfied with their life than the "Ossi's".

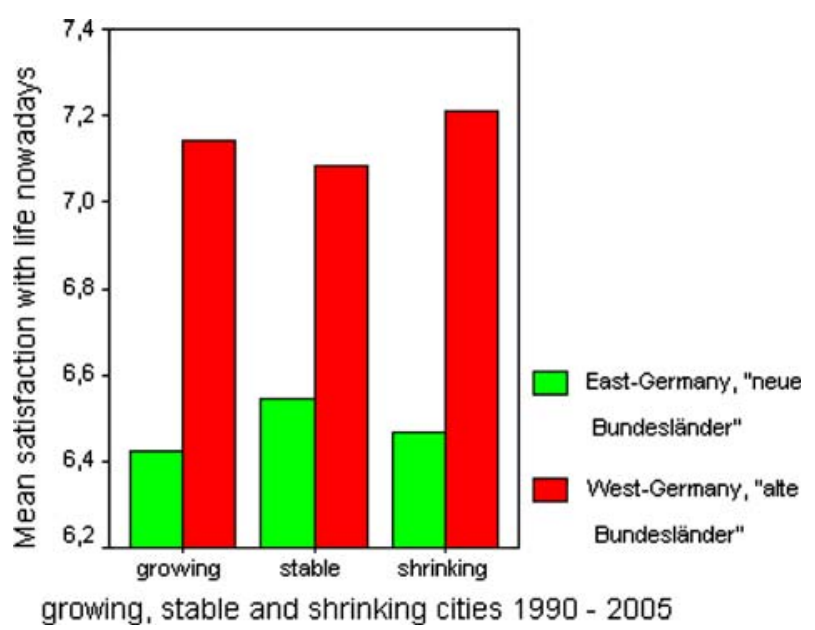

Fig. 3 Satisfaction with present day life in growing, stable and shrinking cities in East and West Germany 


\subsection{Domains of satisfactions in shrinking cities}

Although people in shrinking cities are quite happy with their life, it is conceivable that they are less satisfied with the supply of goods and services in their area and with the local access to public transport. When people start to leave a city, this will affect the public services. The local government will have more financial difficulties in guaranteeing a good infrastructure and public services. Employment in shrinking cities is low, so it is conceivable that employees are less satisfied with their job than employees in growing cities. It is easier to find another job in a growing city. In shrinking cities incomes are lower, so it is also conceivable that inhabitants of shrinking cities are less satisfied with their household income and with their overall standard of living.

The results of this study were surprising. Inhabitants of shrinking cities turned out to be more satisfied with the supply of goods and services than the inhabitants of growing cities; when graded, satisfaction measured 6.3 in growing West-German cities and 6.9 in shrinking West-German cities. The same applies for the local access to public transport; in growing West-German cities the average valuation for public transport was 6.0 and 7.2 in shrinking West-German cities.

There are no significant differences in outcomes for the domains work, household income and standard of living between growing and shrinking cities. That's also a surprising result. Higher unemployment and decreasing perspectives on the labormarket in shrinking cities do not result in a lower satisfaction with work compared to growing cities.

Lower buying power in shrinking cities does not lead to less satisfaction with the household income and standard of living (Table 1).

\section{Concerns in shrinking cities}

The prospects on the labor market in shrinking cities are bad. There are no jobs for the well-educated and unemployment is high. It is easier to make a career in a growing city than in a shrinking city. The economic situation is critical. So there is enough to worry about in shrinking cities. It is conceivable that the inhabitants of shrinking cities have more worries than the inhabitants of growing cities.

The next questions of the SOEP helped me to find an answer:

Table 1 Satisfaction with life-domains in former West Germany (mean and 95\% reliability interval)

\begin{tabular}{llll}
\hline Domains & Growing city & Stable city & Shrinking city \\
\hline Work & $7.1[7.08,7.18]$ & $6.9[6.78,7.00]$ & $7.1[6.96,7.17]$ \\
Household income & $6.6[6.59,6.68]$ & $6.5[6.43,6.60]$ & $6.6[6.51,6.68]$ \\
Supply of goods and services & $\mathbf{6 . 3}[6.29,6.38]$ & $7.0[6.91,7.08]$ & $\mathbf{6 . 9}[6.81,6.99]$ \\
Public transport & $\mathbf{6 . 0}[6.00,6.10]$ & $7.0[6.88,7.06]$ & $\mathbf{7 . 2}[7.10,7.28]$ \\
Environment & $7.0[6.91,6.97]$ & $6.7[6.61,6.74]$ & $6.7[6.67,6.81]$ \\
Standard of living & $7.3[7.23,7.30]$ & $7.2[7.10,7.24]$ & $7.2[7.16,7.30]$ \\
\hline
\end{tabular}


Table 2 West-Germans that are very concerned about different domains of life (percentage and $95 \%$ reliability interval)

\begin{tabular}{llll}
\hline Domains & Growing city & Stabilized city & Shrinking city \\
\hline General economic situation & $51.8[42.0,61.6]$ & $53.4[43.6,63.2]$ & $52.2[42.4,62.0]$ \\
Own economic situation & $\mathbf{1 9 . 6}[11.8,27.4]$ & $21.1[13.1,29.1]$ & $\mathbf{2 8 . 6}[19.7,37.5]$ \\
Maintaining peace & $58.1[48.4,67.8]$ & $59.1[49.5,68.7]$ & $57.8[48.1,67.5]$ \\
Crime & $\mathbf{3 8 . 9}[29.3,48.5]$ & $40.5[30.9,50.1]$ & $\mathbf{4 6 . 5}[36.7,56.3]$ \\
Job security & $\mathbf{1 2 . 3}[5.9,18.7]$ & $14.0[7.2,20.8]$ & $\mathbf{1 8 . 2}[10.6,25.8]$ \\
\hline
\end{tabular}

"What is your attitude towards the following areas - are you concerned about them?" (possible answers: very concerned; somewhat concerned; not concerned at all)

- General economic development

- Your own economic situation

- Maintaining peace

- Crime in Germany

- Your job security

The results were not surprising. In former West German shrinking cities people are more concerned about their own economic situation, about crime and about job security, as Table 2 shows.

\section{Discussion}

Apparently, people can live happily in shrinking cities. Diminishing facilities seem even to have a positive influence on life satisfaction; inhabitants of shrinking cities appear to be more satisfied with the supply of goods and services and with the local access to public transport. Social circumstances like freedom, equality and social networks seem to be more important than prosperity aspects like plenty of facilities.

Still, the economic situation in shrinking cities is a source of concern. The percentage of unemployment in shrinking cities is high. Although people in shrinking cities worry about economic development, it does not seem to have any influence on present day life satisfaction. The answer could possibly be that people can live with some problems and even flourish when confronted with challenge. Living in a shrinking city might be that challenge (Veenhoven, 2005).

My study shows that a shrinking city does not lead to less life satisfaction. You could conclude that there is nothing to worry about. However, I would like to remark the following on the results. My study compares the satisfaction of current inhabitants of shrinking and growing cities. This could distort the real situation. Cities shrink because people are leaving the city. Why do they leave and why do other people stay? The people that have left the shrinking cities did not take part in this study. It is conceivable that diminishing life-satisfaction is the reason to leave a shrinking city. That should mean that the most satisfied people stay. Comparing the life-satisfaction of the persons that leave and the persons that stay is therefore necessary. 


\section{References}

Das sozio-ökonomische Panel, Leben in Deutchland - interviewer handbuch, SOEP, cd-rom 19842003 data, DIW Berlin.

Veenhoven, R. (2005). Happiness in hardship. In: L. Bruni \& P. Porta (Eds.), Economics and happiness: Framing the analyses (pp. 248-266). Oxford University Press.

www.bertelsmann-stiftung.de.

www.bbr.bund.de. 